\title{
Retraction Note: Management of postoperative nausea and vomiting in patients undergoing laparoscopic cholecystectomy
}

\author{
Yoshitaka Fujii
}

Published online: 30 April 2013

(C) Springer Science+Business Media New York 2013

Retraction Note to: Surg Endosc (2011) 25:691-695

DOI 10.1007/s00464-010-1193-9

The Editors-in-Chief are retracting this article because the study on which the article was based was conducted without ethics committee approval.

The online version of the original article can be found under doi:10.1007/s00464-010-1193-9.

Y. Fujii $(\bowtie)$

First Department of Anesthesiology, Toho University School of Medicine, 6-11-1, Ohmori-Nish, Ohta-ku, Tokyo 143-8541,

Japan

e-mail: yfujii@med.toho-u.ac.jp 